Check for updates

Cite this: RSC Adv., 2017, 7, 47975

\title{
A cost-effective birnessite-silicon solar cell hybrid system with enhanced performance for dye decolorization
}

\author{
Guiping Ren, (D) Manyi Sun, Yuan Sun, Yan Li, Changqiu Wang, Anhuai Lu* \\ and Hongrui Ding*
}

A cost-effective and simple configuration of birnessite-silicon solar cell (Bir-SSC) hybrid system is reported in this study. Birnessite, with a band gap of $2.1 \mathrm{eV}$ as determined by UV-vis spectroscopy, was electrochemically deposited on a fluorine-doped tin oxide (FTO) for usage as the anode. It was thoroughly characterized by scanning electron microscopy (SEM), atomic force microscopy (AFM) and Raman spectroscopy, and its prompt response to visible light was further tested by linear sweep voltammetry (LSV). When birnessite electrode was connected with a silicon solar cell in a hybrid system, a remarkably enhanced methyl orange (MO) decolorization from 47.1\% (with a bare SSC) to $95.8 \%$ was observed. The results indicated the synergistic effects of photoelectrochemical and electrochemical reactions in the hybrid system. In addition, the electron utilization efficiency was $15.29 \%$ and $8.54 \%$ with and without light irradiation on birnessite respectively. When applied with three different rated voltage SSC, $2.0 \mathrm{~V}$ SSC showed the best fit in the hybrid system. Cycling experiments exhibited the stable performance of birnessite electrode, where the $\mathrm{MO}$ color removal ratio in ten cycles remained stable at $90.1 \pm 2.5 \%$, which is close to the first cycle (95.8\%). The hybrid system possesses the merits of costeffectiveness, low-power consumption, and "green" fabrication strategy, which exbihits promising potential in solar energy utilization and wastewater treatment.

Received 1st August 2017

Accepted 16th September 2017

DOI: $10.1039 / c 7 r a 08468 d$

rsc.li/rsc-advances reagent, thus exactly meeting the environmental demands. ${ }^{8-14}$ The main efficient electrochemical procedures are electrocoagulation, electroreduction, electrochemical oxidation, indirect electrooxidation with strong oxidants and photoassisted electrochemical methods. ${ }^{8,9}$ The treatment using emerging technologies like photoelectro-Fenton and photoelectrocatalysis (PEC) have been classified as electrochemical advanced oxidation processes (EAOPs).$^{8-11}$ Electrocoagulation is an effective and economical technology for almost total decolorization of chloride dyes. Electrochemical reduction requires higher degradation power cathode materials. $^{8-10}$ Indirect electro-oxidation using strong oxidants (active chlorine or Fenton) along with photoassisted electrochemical applications enhances the efficiency significantly. ${ }^{1,2,5-12}$ Electrochemical oxidation provides a simple, viable way and EAOP is promising for the remediation of chloride-free effluents. ${ }^{8-10}$ Moreover, the combination with nanofiltration, microwaves and ultrasounds opens new perspectives for dyestuff effluents treatment. ${ }^{9}$ Solar energy is employed in photoelectrochemical system leading to a solar PEC (SPEC) process, ${ }^{12-16}$ but little attention has been devoted to solar cells. Solar cells are a stable, low cost and commercialized power generation devices, which can transform solar energy into electric energy and may overcome the drawback of high cost of electrical supply. ${ }^{10}$ The possibilities of combined application of solar cells and photoelectrochemical system remain to be explored.
The Key Laboratory of Orogenic Belts and Crustal Evolution, School of Earth and Space Sciences, Peking University, Beijing Key Laboratory of Mineral Environmental Function, Beijing, China.E-mail: ahlu@pku.edu.cn; DHR@pku.edu.cn 
As far as electrochemical technologies are concerned, selection of electrode is one of the most significant factors. ${ }^{\mathbf{8}, 11}$ Designing and fabricating an electrode of desired composition and characteristics is a challenging task. ${ }^{17}$ Commonly used methods for fabrication of metal oxide anodes are solution/gas phase chemical methods and electrochemical methods (anodization/deposition). The solution-phase method involves dip/spin coating, painting, spray pyrolysis, and sol-gel techniques. The gas-phase methods are chemical vapour deposition and atomic layer deposition. ${ }^{\mathbf{1 8}}$ Moreover, a large variety of electrodes including doped and undoped $\mathrm{PbO}_{2}$; mixed metal oxides of $\mathrm{Ti}, \mathrm{Ru}, \mathrm{Ir}, \mathrm{Sn}$ and $\mathrm{Sb}$ doped-SnO $\mathrm{S}_{2}$; carbonaceous electrodes and boron-doped diamonds are used as anodes for treatment of synthetic dyes..$^{\mathbf{8 - 1 1 , 1 9 - 2 2}}$ In most cases, $\mathrm{TiO}_{2}$ film was used in photocatalysis and PEC process and a few novel photocatalysts responding to visible light, such as $\mathrm{Fe}_{2} \mathrm{O}_{3}, \mathrm{WO}_{3}, \mathrm{ZnO}$, and GaN were developed as well. ${ }^{23-26}$ In recent years, manganese oxides have drawn increasing attention for applications in batteries, supercapacitors and visible light-driven catalysis. ${ }^{27-29}$ Birnessite was one such manganese oxide, which consists of edge-sharing sheets of $\mathrm{MnO}_{6}$ octahedra and has a bandgap of 1.8-2.1 eV (ref. 30-32). Applications of birnessite in oxidation of indigo carmine, benzene and phenolic compounds have been reported. ${ }^{33-36}$ Since manganese is the $10^{\text {th }}$ most abundant element in the earth's crust and is several orders of magnitude cheaper than rare earth metal catalysts such as $\mathrm{Pt}, \mathrm{Pd}$, or $\mathrm{Ru}$, birnessite was a compelling candidate as an electrode material.

In this study, a stable, low-cost and commercialized power generation device-silicon solar cell-was connected with a birnessite electrode in a Bir-SSC hybrid system with the aim to achieve economic and environmental friendly effects. The treatment efficiency of the hybrid system for organic pollutant was tested by a model dye-methyl orange (MO). Moreover, the birnessite electrode characters, MO decolorization efficiency, electron utilization efficiency, system compatibility with different solar cells and the stability of birnessite after ten continuous runs were investigated. By virtue of the simple configuration and good performance, the Bir-SSC hybrid system was believed to be an environment-friendly and lowpower consumption system that could harvest solar energy simultaneously to treat wastewater.

\section{Methods and materials}

\subsection{Birnessite electrode preparation}

Birnessite electrode was prepared by cathodic deposition, which was performed in a three-electrode electrochemical cell at room temperature. ${ }^{37}$ Fluorine-doped tin oxide (FTO), platinum sheet $(1 \mathrm{~cm} \times 1 \mathrm{~cm})$ and a saturated calomel electrode (SCE, $0.244 \mathrm{~V} v s$. normal hydrogen electrode) were used as the working, counter and reference electrode, respectively. Before electrodeposition, the FTO was cleaned by sonication in acetone, ethanol, and distilled water for $30 \mathrm{~min}$ each. The electrodeposition bath consisted of an aqueous solution of $2 \mathrm{mmol} \mathrm{L}^{-1} \mathrm{KMnO}_{4}+50 \mathrm{mmol} \mathrm{L}^{-1} \mathrm{KCl}$. All solutions were prepared from analytical-grade reagents and $18.3 \mathrm{M} \Omega \mathrm{cm}$ Millipore water. The exposed area of the working electrode was 2.5 $\times 4 \mathrm{~cm}^{2}$. A potentio/galvanostat electrochemical workstation (CHI 760E Shanghai Chenhua Instrument, China) was employed to maintain a constant potential of $-0.05 \mathrm{~V}$ (vs. SCE) during the deposit process. The birnessite was controlled with the charge of $0.5 \mathrm{C}$ and then rinsed with distilled water.

\subsection{Characterization of birnessite electrode}

Scanning electron micrographs of birnessite were obtained using a Quanta 650 Field Emission Gun scanning electron microscope (SEM) (FEI, USA) under a high voltage of $15 \mathrm{kV}$ and a pressure of $120 \mathrm{~Pa}$. The samples were mounted on an aluminum SEM stub via conductive tapes and coated with gold using a Denton Desk II Gold Sputter Coater before SEM observations.

In order to acquire more morphology information, thickness measurements of birnessite were performed using Bruker Dimension ICON Atomic Force Microscopy (AFM) (Bruker, USA). The birnessite was partially lifted off the substrate using a scalpel and then the heights were measured for birnessitecoated and uncoated regions beneath the AFM tip. Imaging was performed in ScanAsyst $\AA$ mode over a range of $50 \times 10 \mu \mathrm{m}$. Average step heights along $X$ axis were obtained using the "step" feature in NanoScope_Analysis software.

The mineral phase and structure analysis of birnessite were measured by Raman spectra (Renishaw inVia Reflex, UK) equipped with a $532 \mathrm{~nm}$ laser and a long working-distance $50 \times$ objective. The accuracy of the apparatus and the frequency stability were checked by recording the Raman spectrum of silicon. To obtain a high signal-to-noise ratio, each Raman spectrum was the average of 5 successive scans recorded at a spectral resolution of $1 \mathrm{~cm}^{-1}$. The laser intensity was $50 \%$ and the diameter of the beam spot was $1 \mu \mathrm{m}$.

As a semiconducting material, the value of optical band gap was determined by UV-vis absorption spectroscopy (UV 3600Plus, Japan) in transmission mode with baseline correction for the bare FTO substrate.

The photoresponse of birnessite electrode was measured by a quartz cube cell with a conventional three-electrode configuration system under chopped irradiation from an external simulated LED (Light Emitting Diode) and the illumination

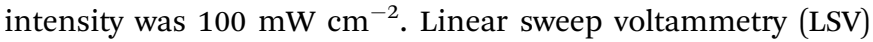
was performed in the electrolyte with $0.1 \mathrm{~mol} \mathrm{~L}^{-1} \mathrm{Na}_{2} \mathrm{SO}_{4}+$ $1.0 \mathrm{~mol} \mathrm{~L}^{-1}$ ethanol aqueous solution using a potentiostat (CHI 1000C Shanghai Chenhua Instrument, China). Hand-chopped light was used to obtain the light and dark curves and the scan rate for the linear sweep voltammetry was $2.5 \mathrm{mV} \mathrm{s}^{-1}$.

\subsection{Hybrid system configuration}

The Bir-SSC hybrid system was based on an electrolytic cell (Fig. 1). Birnessite electrode, platinum sheet and a saturated calomel electrode were used as the working, counter and reference electrode, respectively. The positive electrode of SSC was connected with birnessite electrode; the negative electrode was linked to a unit of $1000 \Omega$ resistance and then connected with the cathode. The voltage of the resistance was recorded 


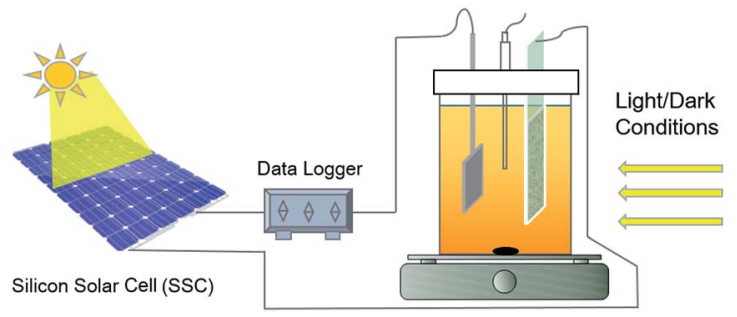

Fig. 1 Schematic of the Bir-SSC hybrid system.

using a datalogger (ADC-16, Pico Technology, UK). Electrode potentials were recorded simultaneously using a digital voltmeter (UT-33B, China).

At first, the adsorption and photodecomposition of MO by birnessite electrode was studied. Then, a SSC was introduced to the linear circuit and the decolorization ability of Bir-SSC hybrid system under light and dark conditions for birnessite electrode were investigated. Moreover, the feasibility and compatibility of the hybrid system equipped with different standard SSCs was further explored. In order to understand the long-term cycle of the hybrid system and stability of birnessite electrode, ten continuous runs for decolorization of MO was carried out. Then, morphology and structure of the electrodes were comparatively studied by Raman, SEM and AFM techniques.

\subsection{Photoelectrocatalytic decolorization characterization}

Photoelectrocatalytic decolorization of MO was performed at room temperature in a cylindrical quartz glass electrolytic cell containing $30 \mathrm{~mL} 5 \mathrm{mg} \mathrm{L}{ }^{-1} \mathrm{MO}$ aqueous solution. During the course of the experiment, the $\mathrm{pH}$ of the decolorization solution was not controlled, but monitored using a Mettler Toledo $\mathrm{pH}$ meter before $(\mathrm{pH}=5.6)$ and after $(\mathrm{pH}=5.6)$ the decolorization process. The incident light was irradiated onto birnessite electrodes from the backside through the quartz window. The light intensity at sample position was approximately $200 \mathrm{~mW} \mathrm{~cm} \mathrm{~cm}^{-2}$, provided by an external white LED lamp.

The decolorization efficiency of MO was evaluated by monitoring the absorbance at the maximum absorption wavelength of $464 \mathrm{~nm}$ using a UV-visible spectrometer (Evolution 220, Thermo, USA). The efficiency of the MO decolorization was estimated using eqn (1):

$$
\text { MO decolorization }(\%)=\left(A_{0}-A_{t}\right) / A_{0} \times 100 \%
$$

where $A_{0}$ and $A_{t}$ are the absorbance at initial time and time $t$ at the $\lambda_{\max }$ of the MO respectively. The rate of MO decolorization could be described by a zero-order model eqn (2) or pseudo-first order model eqn (3):

$$
\begin{gathered}
C_{t}-C_{0}=-k_{0} \mathrm{t} \\
\ln \left(C_{t} / C_{0}\right)=-k_{1} \mathrm{t}
\end{gathered}
$$

where $k_{0}\left(\mathrm{mg} \mathrm{L}^{-1} \mathrm{~h}^{-1}\right)$ and $k_{1}\left(\mathrm{~h}^{-1}\right)$ are the rate constants for the decolorization reaction.

\section{Results and discussion}

\subsection{Morphology and structure characterization of birnessite electrode}

After potentiostatic electrodeposition, a birnessite film, composed of wrinkled thin sheets, was formed on the FTO electrode (using SEM, as shown in Fig. 2), which was consistent with previously reported synthesized birnessite films. ${ }^{30,37}$ All the sheets were perpendicular to the FTO electrode and assembled to a porous structure, which facilitated the access of the electrolyte. The thickness of the film was approximately $200 \mathrm{~nm}$ as measured by AFM. Even after ten times of reuse, no significant changes in the birnessite film were observed and the thickness remained at $200 \mathrm{~nm}$, indicating physical stability of birnessite electrode.

Raman spectra (Fig. 3) showed three bands at 514, 578 and $641 \mathrm{~cm}^{-1}$, which nearly matched the major vibrational modes of birnessite. ${ }^{38}$ The Raman band located at $641 \mathrm{~cm}^{-1}$ was attributed to the symmetric stretching vibration $\nu_{2}(\mathrm{Mn}-\mathrm{O})$ of $\mathrm{MnO}_{6}$ groups. The strongest band located at $578 \mathrm{~cm}^{-1}$ was attributed to the $\nu_{3}(\mathrm{Mn}-\mathrm{O})$ stretching vibration in the basal plane of $\mathrm{MnO}_{6}$ sheets. ${ }^{38,39}$ The low-wavenumber Raman $\left(<500 \mathrm{~cm}^{-1}\right)$ peaks were associated with $\mathrm{K}-\mathrm{O}$ vibrations. Consistent with the morphology characteristics, the Raman patterns before and after 10 times cycling test showed no observable changes, indicating the chemical stability of the birnessite electrode.

\subsection{Band gap and photocurrent of birnessite}

Fig. 4 (inset picture) displayed the UV-vis absorption spectrum of birnessite electrode, which exhibits broad absorptions in the wavelength range of 300-700 $\mathrm{nm}$. The electronic transition between the valence and conduction bands consists primarily of an excitation from an $\mathrm{O}(2 \mathrm{p})$ to $\mathrm{Mn}(3 \mathrm{~d})$ and with some $\mathrm{Mn}(3 \mathrm{~d})$ to $\mathrm{Mn}(3 \mathrm{~d})$ character..$^{32,40}$ A distinct peak is located at around $400 \mathrm{~nm}$, which could be ascribed to the overlap of the $d-d$ transitions of manganese ions in the octahedral site. ${ }^{41}$ The Tauc plots and absorption spectrum for birnessite is shown in Fig. 4. The extrapolated results indicated an allowed indirect band gap of $2.1 \mathrm{eV}$ and an allowed direct band gap of $2.3 \mathrm{eV}$. A previous study had reported that synthetic Na-birnessite (approximately $\mathrm{Na}_{4} \mathrm{Mn}_{14} \mathrm{O}_{27}$ ) had a band gap of $1.8 \mathrm{eV}$ (ref. 35) and synthesized protonic birnessite $\left(\mathrm{H}_{0 \cdot 13} \mathrm{MnO}_{2} \cdot 0.7 \mathrm{H}_{2} \mathrm{O}\right)$ had a band gap of $2.23 \mathrm{eV}$. In addition, electrodeposited crystalline Na birnessitetype $\mathrm{MnO}_{2}$ thin film exhibited an indirect band gap of $2.1 \mathrm{eV}$
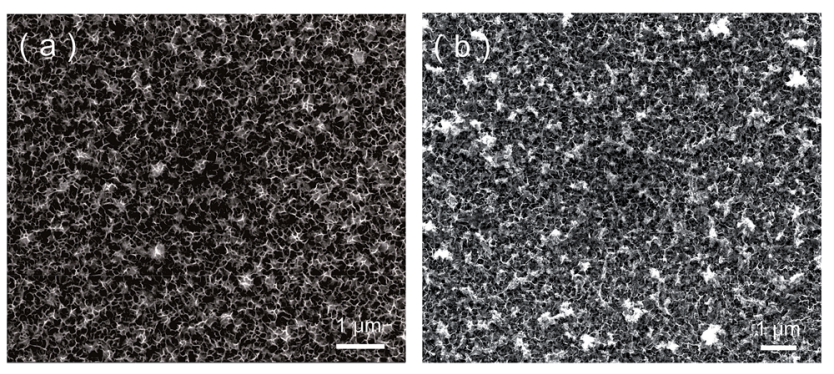

Fig. 2 SEM images of birnessite before (a) and after (b) 10 times of reuse for $\mathrm{MO}$ decolorization. 


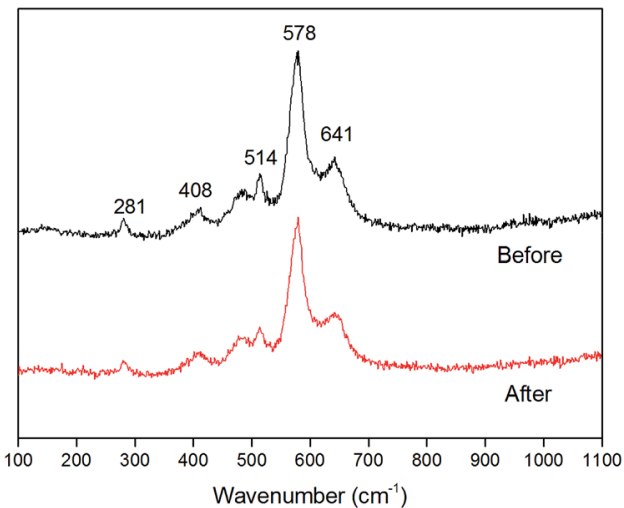

Fig. 3 Raman spectra of birnessite electrode before and after 10 times of reuse for $\mathrm{MO}$ decolorization.

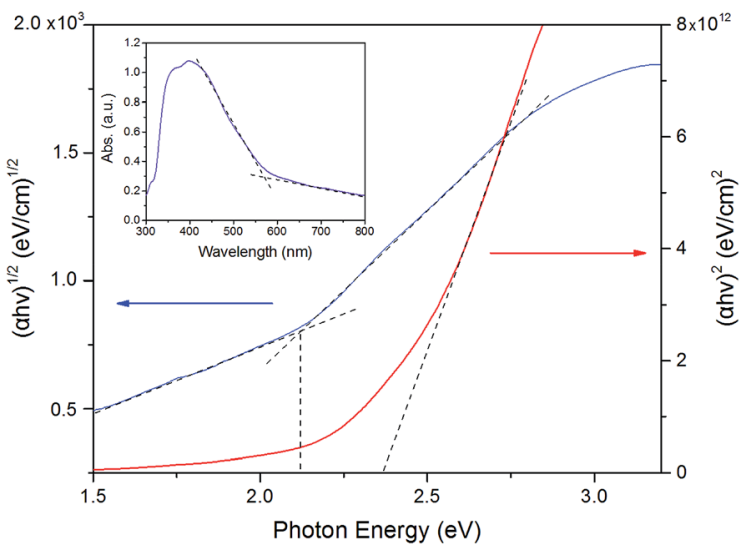

Fig. 4 Tauc plots of birnessite for determining the indirect $(2.1 \mathrm{eV})$ and direct $(2.3 \mathrm{eV}$ ) band gaps (inset picture: UV-vis absorption spectra for birnessite electrode).

and an allowed direct band gap of $2.7 \mathrm{eV}$ (ref. 31,42). Based on the laboratory results of different birnessite films, we concluded that the birnessite electrode was a visible-light photoactive material.

Furthermore, photocurrent density of birnessite electrode responding to different potentials under visible-light illumination was investigated by LSV curves. As shown in Fig. 5 (inset picture), the photocurrent immediately increased when light was turned on and rapidly went back to base line when light was switched off. The anodic photocurrents corresponding to a photo-oxidation process indicated that birnessite had an n-type semiconducting nature. ${ }^{30,42,43}$ Moreover, the behavior of photocurrent generation was influenced by potential change. With higher potential, the increment of photocurrent was more significant and when the anodic potential increased to $1.2 \mathrm{~V}$, the value of photocurrent was almost three times higher than dark current (Fig. 5). The result suggested that the separation of electron-hole pairs was more effective at higher anodic potential.

\subsection{Photoelectrocatalytic decolorization of MO in the hybrid system}

The MO decolorization efficiencies at different controls were compared with each other. As shown in Fig. 6, the "Dark + Bir"

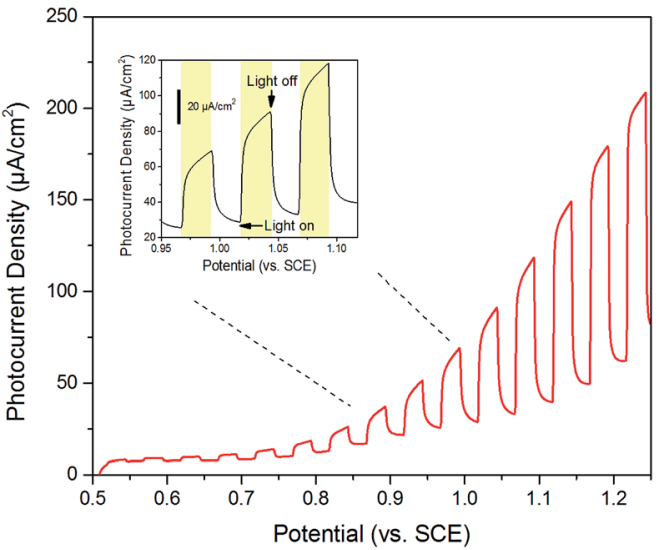

Fig. 5 Current potential curve (anodic sweep at $2.5 \mathrm{mV} \mathrm{s}^{-1}$ shown) for birnessite showing $\mathrm{n}$-type photocurrent and reasonable catalytic activity.

experimental group showed no evident decolorization effect, which indicated that the adsorption of MO by birnessite electrode was negligible. Moreover, the concentration of MO did not decrease in the "Light + Bir" experimental group. This suggested that the direct photodecomposition of MO by birnessite could not take place. However, when an external SSC (opencircuit voltage was $2.0 \mathrm{~V}$ and short-circuit current was $5.0 \mathrm{~mA}$ ) was employed in the system, "Dark + Bir + SSC", decolorization reaction took place (Fig. 6). After 4 hours, color removal ratio was $47.1 \%$ attributing to electrochemical MO decolorization and the kinetics of MO decrease fitted well with the zero-order kinetic model with rate constants $\left(k_{0}\right)$ of $0.59 \mathrm{mg} \mathrm{L}^{-1} \mathrm{~h}^{-1}$ and $R^{2}$ values of 0.992 . The results revealed that SSC pulled the electrons out from the anode, thus leading to an electrocatalytic oxidation process.

Notably, the highest MO color removal ratio was achieved in the "Light + Bir + SSC" experimental group (95.8\%). The kinetics of MO decolorization followed the pseudo first-order kinetic model with the rate constant $\left(k_{1}\right)$ of $0.79 \mathrm{~h}^{-1}$ and $R^{2}$ value of 0.997. In addition, the total organic carbon (TOC) values of samples before and after decolorization in the hybrid system

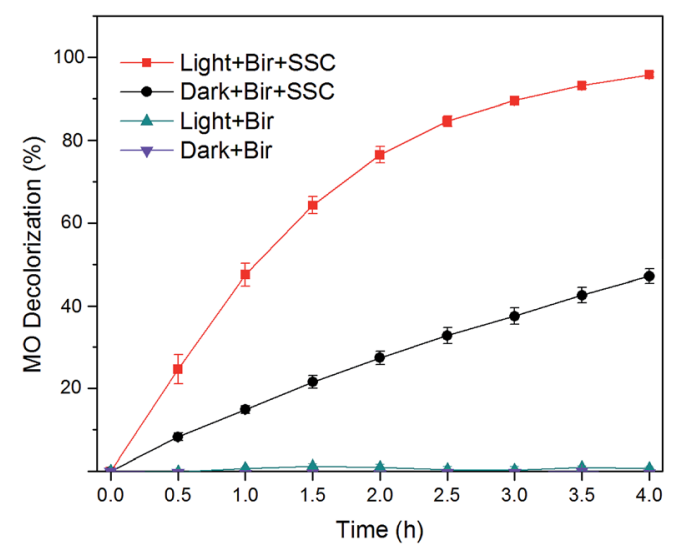

Fig. 6 Decolorization curves for MO in different controls. 
were calculated to be 2.25 and $2.11 \mathrm{mg} \mathrm{L}^{-1}$. It means that although the color of MO was removed, MO did not completely degrade to $\mathrm{CO}_{2}$ and could form more recalcitrant by-products and a large number of intermediates. ${ }^{\mathbf{4 4 - 4 7}}$ Previous studies found that the photoelectrocatalysis method could decolorize different dyes completely, but TOC removal was much lower. ${ }^{8}$ Garcia-Segura reported that TOC reduced only by $40 \%$ in solar PEC for AOPs. ${ }^{\mathbf{8}, 12}$ The results indicated that by-products were formed during degradation process.

Comparing with the recent treatment techniques, such as electrocoagulation, electrochemical reduction, electrochemical oxidation, indirect electro-oxidation and photoassisted electrochemical applications, this hybrid system provided a novel idea for solar energy utilization and wastewater treatment. Light was not only used as a photocatalyst, but also for electrochemical power supply. Based on these results, it can be said that the future looks bright for the use of this hybrid system coupling with various SSC in the field of electrochemical advanced oxidation processes.

\subsection{Electron utilization efficiency in the hybrid system}

To gain more insight, the system electric quantity and the utilized electrons for MO decolorization was calculated according to the current (calculated by voltage of fixed resistance recorded by datalogger) and decolorization ratio data (Fig. 7). The average current in "Light + Bir + SSC" was $15 \mu \mathrm{A}$, while it was only $7 \mu \mathrm{A}$ in "Dark + Bir + SSC". To facilitate comparison, the total transferred electrons, utilized electrons for MO decolorization and the electrons utilization efficiency at the anode are summarized in Table 1 . The electric quantity of "Light + Bir + SSC" was only 2.35 times of "Dark + Bir + SSC". Nevertheless, the total quantity of reduced MO was more significant and up to an amazing relative percentage of $426.5 \%$. Moreover, the electron utilization efficiency was $8.99 \%$ compared with $4.96 \%$ in dark condition. Above all, we could conclude that Bir-SSC hybrid system had higher electron utilization efficiency, demonstrating that MO decolorization was promoted at the birnessite electrode and the energy of visible

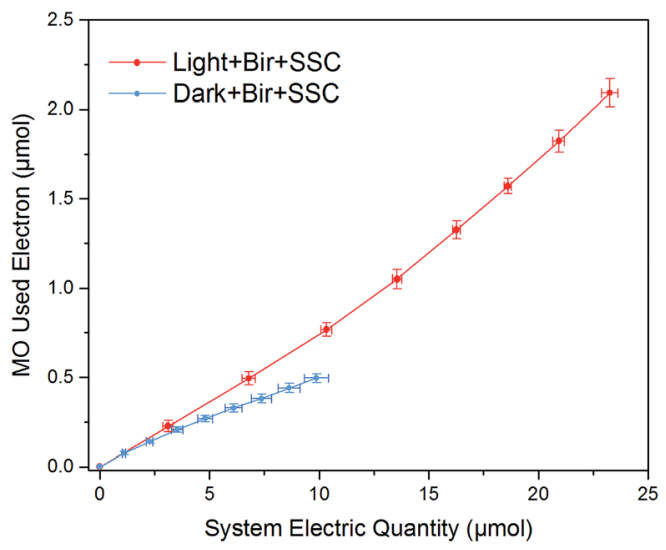

Fig. 7 Correlations of total electrons in the circuit and the electrons used for MO decolorization in Bir-SSC hybrid system under light and dark.
Table 1 Quantity of MO decolorization utilized electron, system electron and electron utilization efficiency

\begin{tabular}{llll}
\hline & $\begin{array}{l}\text { MO decolorization } \\
\text { utilized }(\mu \mathrm{mol})\end{array}$ & $\begin{array}{l}\text { System electric } \\
\text { quantity } \\
(\mu \mathrm{mol})\end{array}$ & $\begin{array}{l}\text { Utilization } \\
\text { efficiency }\end{array}$ \\
\hline Light + Bir + SSC & $2.09 \pm 0.08$ & $23.25 \pm 0.36$ & $8.99 \%$ \\
Dark + Bir + SSC & $0.49 \pm 0.03$ & $9.88 \pm 0.56$ & $4.96 \%$ \\
Relative percentage & $426.53 \%$ & $235.32 \%$ & $181.25 \%$
\end{tabular}

light was used by the hybrid system. Such a promotion was clearly due to the synergistic mechanism of photoelectrocatalysis and electrocatalysis.

\subsection{Compatibility of birnessite electrode with SSC}

With the aim to achieve a better understanding of the performance for the hybrid system, the feasibility and stability of the hybrid system equipped with various specifications of SSC were further investigated (Fig. 8). Three types of SSC (open-circuit voltages were $0.5,1.0,2.0 \mathrm{~V}$ ) were applied to the external circuit in the experiments. MO decolorization ratios in "Light + Bir + SSC", with SSC voltage from low to high reached $33.7 \%$, $81.9 \%$ and $95.1 \%$ in a span of 4 hours. The kinetics of MO decolorization effectively followed the zero-order kinetic model, with rate constants $\left(k_{1}\right)$ of $0.10,0.44$ and $0.77 \mathrm{~h}^{-1}\left(R^{2}=0.987\right.$, 0.997 and 0.997$)$. Nevertheless, it was only $14.5 \%, 43.8 \%$ and $52.4 \%$ at "Dark + Bir + SSC" condition. The kinetics of MO removal fitted the zero-order kinetic model (Table 2), with rate constants $\left(k_{0}\right)$ of $0.18,0.55$ and $0.62 \mathrm{mg} \mathrm{L}^{-1} \mathrm{~h}^{-1}\left(R^{2}=0.997\right.$, 0.996 and 0.999 ). Therefore, when referring to the enhancement of the decolorization efficiency in the hybrid system, SSC exerted influence in two ways. On the one hand, a SSC with higher open-circuit voltage was applied in the hybrid system, which accelerated the separation of electron-hole pairs and produced more oxidative species. On the other hand, the higher voltage SSC produced a larger current and the electrochemical oxidation enhanced at the same time.

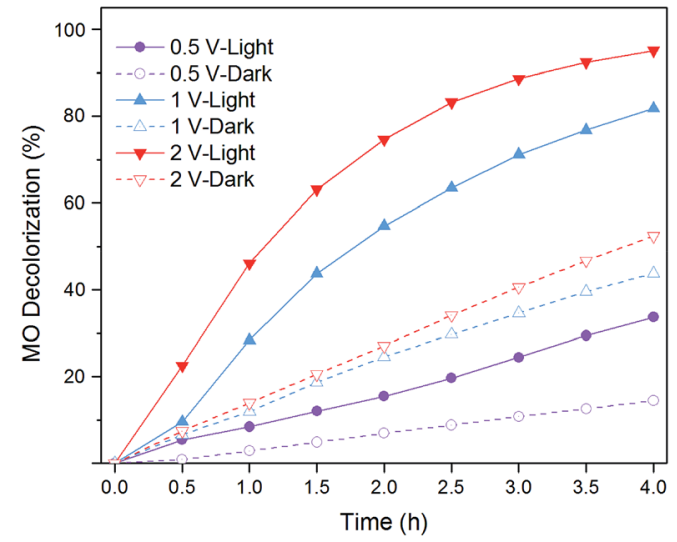

Fig. $8 \mathrm{MO}$ decolorization ratios in Bir-SSC hybrid system coupling with different rated voltage SSCs. 
Table 2 Quantity of $\mathrm{MO}$ decolorization ratio, constant and correlation coefficients for hybrid system coupling with different voltage SSC

\begin{tabular}{lllll}
\hline & SSC & $0.5 \mathrm{~V}$ & $1.0 \mathrm{~V}$ & $2.0 \mathrm{~V}$ \\
\hline \multirow{2}{*}{ Dark + Bir + SSC } & Decolorization ratio in $4 \mathrm{~h}$ & $14.5 \%$ & $43.8 \%$ & $52.4 \%$ \\
& Constant $k_{0}\left(\mathrm{mg} \mathrm{L}^{-1} \mathrm{~h}^{-1}\right)$ & 0.18 & 0.55 & 0.62 \\
& Correlation coefficient $R^{2}$ & 0.997 & 0.996 & 0.999 \\
Light + Bir + SSC & Decolorization ratio in $4 \mathrm{~h}$ & $33.7 \%$ & $81.9 \%$ & $95.1 \%$ \\
& Constant $k_{1}\left(\mathrm{~h}^{-1}\right)$ & 0.10 & 0.44 & 0.77 \\
& Correlation coefficient $R^{2}$ & 0.987 & 0.997 & 0.997
\end{tabular}

It is worthwhile to mention that the percent MO decolorization at an irradiated birnessite anode by SSC $(0.5,1.0$ and 2.0 V) were $98.99 \%, 113.8 \%$ and $144.3 \%$ (at $2.5 \mathrm{~h}$ ), respectively. The results indicated that birnessite showed the most significant photoelectrochemical process with $2.0 \mathrm{~V} \mathrm{SSC}$. At a lower voltage the separation of electron hole pairs was inefficient, but at a higher voltage SSC enhanced the electrochemical oxidation, which weakened the effect of birnessite to some extent.

\subsection{Long-term cycle and stability testing}

The stability of the hybrid system and birnessite electrode for photoelectrocatalysis decolorization of pollutants was tested by successive decolorization of MO for ten continuous runs. The birnessite electrode after decolorization reaction was analyzed by Raman spectroscopy (Fig. 3), which confirmed that the birnessite phase was stable on the FTO electrode. In addition, this was consistent with the observation from SEM (Fig. 2) and the thickness of birnessite film measured by AFM. Moreover, the decolorization efficiencies in ten cycles remained stable at the range of $90.1 \pm 2.5 \%$, which is very close to the first cycle (95.8\%) as shown in Fig. 9, indicating that the birnessite film on electrode was stable when the decolorization experiments were repeated 10 times. The concentration of $\mathrm{Mn}^{2+}$ in the solutions was determined by ICP-OES (Spectroblus, Spectro, Germany). However, no $\mathrm{Mn}^{2+}$ ions were detected in the decolorization solutions after the decolorization of MO finished, meaning that

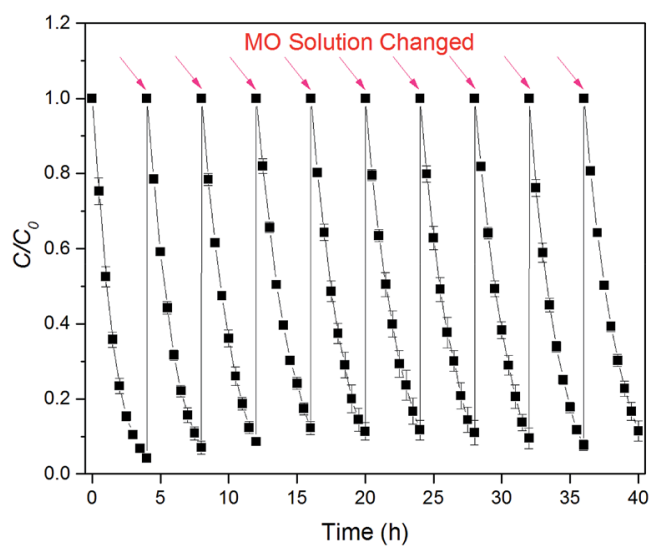

Fig. 9 Cycling decolorization of MO by Bir-SSC hybrid system under visible light illumination. no obvious ions leakage occurred during the decolorization process.

All the results obtained inferred the high stability of electrode in Bir-SSC hybrid system for decolorization of environmental pollutants. Therefore, the future looks bright, as more efficient materials may be employed in the hybrid system.

\subsection{Possible photoelectrocatalysis mechanism}

From the photoelectrocatalytic decolorization results (Fig. 6), we can conclude that without SSC, the electron transfer rate at the birnessite anode was too low to be measured. Even under irradiation, photoelectrons could not be effectively separated to enter into the circuit, which could be due to the lower conduction band potential and poor electron-hole separation efficiency of birnessite. With the help of SSC, an external bias was imposed, which significantly increased the photoelectron transfer rate and prevented the recombination of the photoelectron-hole pairs. The synergistic effect of photoelectrochemical and electrochemical oxidation was realized in the Bir-SSC hybrid system. In addition, the electron was promoted from the valence band to the conduction band, leaving behind a hole in the valence band and reacting with MO. The azo group might convert to amines, which is related to the disappearing of the orange color. ${ }^{45}$ Moreover, TOC values changed slightly in the hybrid system, which indicates that $\mathrm{MO}$ did not completely degrade to $\mathrm{CO}_{2}$. The process of methylation and hydroxylation might take place and result in plenty of intermediates. ${ }^{\mathbf{4 4 - 4 7}}$ In addition, by-products of MO may be similar to those of photocatalytic degradation process. ${ }^{46}$ The proposed schematic mechanism is shown in Fig. 10. For further studies, semiconducting materials with higher efficiency, more suitable operating conditions and better reactor design can be investigated using our proposed hybrid system. Moreover, with a better utilization for solar energy by diverse SSC, it is possible to achieve the goal of coupling of cathodic and anodic processes and enhancement efficiency for wastewater remediation by new electrochemical advanced oxidation processes in the future.

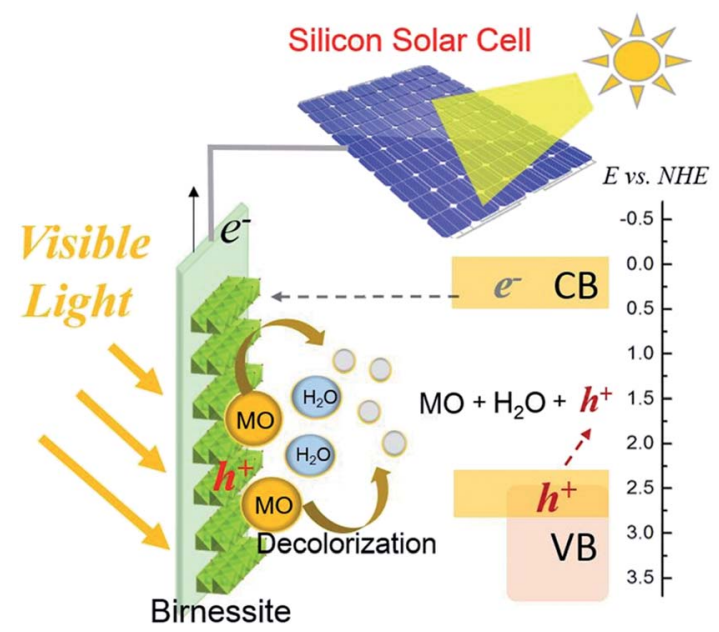

Fig. 10 Schematic of the proposed possible mechanism for the BirSSC hybrid system. 


\section{Conclusions}

We investigated the enhanced performance of photoelectrocatalysis decolorization application using a low-cost BirSSC hybrid system fabricated in this study. SEM, AFM and Raman spectroscopy were used to characterize birnessite electrode. Moreover, UV-vis spectroscopy and electrochemical techniques indicated that birnessite has photoactive material response to visible light. Photoelectrocatalytic decolorization results demonstrated that photoelectrochemical and electrochemical oxidation acted synergistically in the hybrid system. As a result, both the decolorization rate and electron utilization efficiency were significantly improved. Furthermore, different rated voltage SSCs were employed in the hybrid system and the 2.0 V SSC showed the most significant photoelectrochemical process. Cycle and stability testing showed that the birnessite electrode has stable decolorization efficiencies after 10 repeated experiments. Such a system was believed to be an environmentfriendly and low-cost system that could have the potential to be a powerful tool for the degradation of hazardous organics in water.

\section{Conflicts of interest}

There are no conflicts to declare.

\section{Acknowledgements}

This study was funded by the National Basic Research Program of China (973 Program) (Grant No. 2014CB846001) and the Natural Science Foundation of China (Grant No. 41230103, 41522201 \& 41402032).

\section{References}

1 T. Robinson, G. McMullan, R. Marchant and P. Nigam, Bioresour. Technol., 2001, 77(3), 247-255.

2 E. Forgacs, T. Cserhati and G. Oros, Environ. Int., 2004, 30(7), 953-971.

3 A. Bousher, X. Shen and R. G. Edyvean, Water Res., 1997, 31(8), 2084-2092.

4 M. Panizza and G. Cerisola, Chem. Rev., 2009, 109(12), 65416569.

5 I. Oller, S. Malato and J. A. Sánchez-Pérez, Sci. Total Environ., 2011, 409(20), 4141-4166.

6 O. J. Hao, H. Kim and P. C. Chiang, Crit. Rev. Environ. Sci. Technol., 2000, 30(4), 449-505.

7 C. A. Martínez-Huitle, M. A. Rodrigo, I. Sires and O. Scialdone, Chem. Rev., 2015, 115(24), 13362-13407.

8 C. A. Martínez-Huitle and E. Brillas, Appl. Catal., B, 2009, 87(3), 105-145.

9 E. Brillas and C. A. Martínez-Huitle, Appl. Catal., B, 2015, 166, 603-643.

10 I. Sirés, E. Brillas, M. A. Oturan, M. A. Rodrigo and M. Panizza, Environ. Sci. Pollut. Res., 2014, 21(14), 83368367.
11 C. A. Martinez-Huitle and S. Ferro, Chem. Soc. Rev., 2006, 35(12), 1324-1340.

12 S. Garcia-Segura, S. Dosta, J. M. Guilemany and E. Brillas, Appl. Catal., B, 2013, 132, 142-150.

13 S. Garcia-Segura, L. C. Almeida, N. Bocchi and E. Brillas, J. Hazard. Mater., 2011, 194, 109-118.

14 R. Salazar, E. Brillas and I. Sirés, Appl. Catal., B, 2012, 115, 107-116.

15 R. Salazar, S. Garcia-Segura, M. S. Ureta-Zañartu and E. Brillas, Electrochim. Acta, 2011, 56(18), 6371-6379.

16 F. C. Moreira, S. Garcia-Segura, V. J. P. Vilar, R. A. Boaventura and E. Brillas, Appl. Catal., B, 2013, 142, 877-890.

17 A. N. Subba Rao and V. T. Venkatarangaiah, Environ. Sci. Pollut. Res., 2014, 21(5), 3197-3217.

18 D. Perednis and L. J. Gauckler, J. Electroceram., 2005, 14(2), 103-111.

19 X. Li, D. Pletcher and F. C. Walsh, Chem. Soc. Rev., 2011, 40(7), 3879-3894.

20 Y. J. Feng and X. Y. Li, Water Res., 2003, 37(10), 23992407.

21 M. Panizza and G. Cerisola, Chem. Rev., 2009, 109(12), 65416569.

22 N. N. Rao, K. M. Somasekhar, S. N. Kaul and L. Szpyrkowicz, J. Chem. Technol. Biotechnol., 2001, 76(11), 1124-1131.

23 A. M. Basilio, Y. K. Hsu and K. H. Chen, Mater. Chem., 2010, 20, 8118.

24 X. F. Cheng, W. H. Leng, D. P. Liu, J. Q. Zhang and C. N. Cao, Chemosphere, 2007, 68(10), 1976-1984.

25 S. S. Shinde, C. H. Bhosale and K. Y. Rajpure, Catal. Rev.: Sci. Eng., 2013, 55(1), 79-133.

26 Y. K. Hsu, Y. G. Lin and Y. C. Chen, Electrochem. Commun., 2011, 13(12), 1383-1386.

27 F. Jiao and H. Frei, Energy Environ. Sci., 2010, 3(8), 10181027.

28 A. R. Armstrong and P. G. Bruce, Nature, 1996, 381(6582), 499.

29 C. C. Hu and T. W. Tsou, Electrochem. Commun., 2002, 4(2), 105-109.

30 Y. K. Hsu, Y. C. Chen, Y. G. Lin, L. C. Chen and K. H. Chen, J. Mater. Chem., 2012, 22(6), 2733-2739.

31 B. A. Pinaud, Z. Chen, D. N. Abram and T. F. Jaramillo, J. Phys. Chem. B, 2011, 115(23), 11830-11838.

32 D. M. Sherman, Geochim. Cosmochim. Acta, 2005, 69(13), 3249-3255.

33 S. C. Chien, H. L. Chen, M. C. Wang and K. Seshaiah, Chemosphere, 2008, 74(8), 1125-1133.

34 J. Hou, Y. Li, M. Mao, L. Ren and X. Zhao, ACS Appl. Mater. Interfaces, 2014, 6(17), 14981-14987.

35 M. Zaied, E. Chutet, S. Peulon, N. Bellakhal, B. Desmazières, M. Dachraoui and A. Chaussé, Appl. Catal., B, 2011, 107(1), 42-51.

36 H. Zhang, H. Ding, X. Wang, C. Zeng, A. Lu, Y. Li and C. Wang, J. Environ. Sci., 2017, 52, 259-267.

37 M. Nakayama, T. Kanaya, J. W. Lee and B. N. Popov, J. Power Sources, 2008, 179(1), 361-366. 
38 C. Julien, M. Massot, R. Baddour-Hadjean, S. Franger, S. Bach and J. P. Pereira-Ramos, Solid State Ionics, 2003, 159(3-4), 345-356.

39 Y. K. Hsu, Y. C. Chen, Y. G. Lin, L. C. Chen and K. H. Chen, Chem. Commun., 2011, 47(4), 1252-1254.

40 K. D. Kwon, K. Refson and G. Sposito, Geochim. Cosmochim. Acta, 2009, 73(14), 4142-4150.

41 E. J. Oh, T. W. Kim, K. M. Lee, M. S. Song, A. Y. Jee, S. T. Lim and S. J. Hwang, ACS Nano, 2010, 4(8), 4437-4444.

42 N. Sakai, Y. Ebina, K. Takada and T. Sasaki, J. Phys. Chem. B, 2005, 109(19), 9651-9655.
43 Y. Ohko, K. Hashimoto and A. Fujishima, J. Phys. Chem. A, 1997, 101(43), 8057-8062.

44 K. Dai, H. Chen, T. Peng, D. Ke and H. Yi, Chemosphere, 2007, 69(9), 1361-1367.

45 L. G. Devi, S. G. Kumar, K. M. Reddy and C. Munikrishnappa, J. Hazard. Mater., 2009, 164(2), 459-467.

46 C. Baiocchi, M. C. Brussino, E. Pramauro, A. B. Prevot, L. Palmisano and G. Marci, Int. J. Mass Spectrom., 2002, 214, 247-256.

47 Y. P. Chen, S. Y. Liu, H. Q. Yu, H. Yin and Q. R. Li, Chemosphere, 2008, 72(4), 532-536. 